\title{
West Nile Virus Infection in Mosquitoes, Birds, Horses, and Humans, Staten Island, New York, 2000
}

\author{
Varuni L. Kulasekera,* Laura Kramer,† Roger S. Nasci,‡ Farzad Mostashari,§ \\ Bryan Cherry,* Susan C. Trock, , Carla Glaser,* and J ames R. Miller* \\ *New York City Department of Health, New York, New York, USA; †New York State Department of \\ Health, Albany, New York, USA; †Centers for Disease Control and Prevention, Fort Collins, \\ Colorado, USA; §OutbreakDetect Inc., New York, New York, USA; and ITCornell University, Ithaca, \\ New York, and New York State Department of Agriculture and Markets, Albany, New York, USA
}

\begin{abstract}
West Nile (WN) virus transmission in the United States during 2000 was most intense on Staten Island, New York, where 10 neurologic illnesses among humans and 2 among horses occurred. WN virus was isolated from Aedes vexans, Culex pipiens, Cx. salinarius, Ochlerotatus triseriatus, and Psorophora ferox, and WN viral RNA was detected in Anopheles punctipennis. An elevated weekly minimum infection rate (MIR) for Cx. pipiens and increased dead bird density were present for 2 weeks before the first human illness occurred. Increasing mosquito MIRs and dead bird densities in an area may be indicators of an increasing risk for human infections. A transmission model is proposed involving $C x$. pipiens and $C x$. restuans as the primary enzootic and epizootic vectors among birds, $C x$. salinarius as the primary bridge vector for humans, and Aedes/Ochlerotatus spp. as bridge vectors for equine infection.
\end{abstract}

During the 1999 outbreak of West Nile (WN) virus in the greater New York City (NYC) area, surveillance for virus in mosquito populations did not begin until early September, when the epidemic among humans had already peaked (1). From September through October 1999, WN virus was isolated from nine NYC mosquito pools, including two pools of Culex pipiens, six pools of unidentified Culex species, and one pool of mixed $C x$. pipiens/restuans. The mosquitoes were identified by using morphologic characters. Subsequent molecular testing of two of the unidentified Culex sp. pools revealed that they were composed of $C x$. restuans and $C x$. salinarius (2). Evidence of WN virus infection was found in both dead and live wild birds in NYC in the 1999 outbreak, but there was no systematic monitoring of dead bird sightings in the weeks preceding the first human illness or during the human epidemic.

In anticipation of a possible return of WN virus during 2000 , the NYC Department of Health (NYCDOH) established a citywide network of adult mosquito traps and systematically monitored dead bird sightings as part of a comprehensive program for surveillance, prevention, and control of WN virus in the city. An integrated mosquito management program was initiated throughout the city, which included breeding site elimination, larval control, and public education that encouraged residents to remove mosquito sources from their property and to use personal protective behaviors to avoid mosquito bites.

Address for correspondence: Varuni Kulasekera, Room 619, CN 32P, New York City Department of Health, 125 Worth Street, New York, New York 10013, USA; fax: 212-442-5215; e-mail: vkulasek@health.nyc.gov
The first dead bird on Staten Island (SI) in 2000 with laboratory evidence of WN virus was found on July 5 , and the first mosquitoes with laboratory evidence of WN virus were collected on SI on July 7. By the end of the mosquito-borne disease transmission season, SI had 71\% (10/14) of NYC's human cases, as well as $77 \%$ (131/170) of mosquito pools and $33 \%$ (61/185) of dead birds with laboratory evidence of WN virus.

SI, one of the five NYC boroughs. has a surface area of 60.2 square miles (156 square kilometers) and a population of 378,977 (3). The population density is 6,295 persons/square mile, less than the density of the other four boroughs (range by borough: 17,409 to 62,765$)$. SI has 115 acres/square mile of park land, compared with the average 80 acres/square mile in the other four boroughs (range by borough: 54 to 155) (3). This island also has $88 \%(2,942 / 3,350$ acres $)$ of NYC's freshwater wetlands (GIS Unit, Region 2, New York State Department of Environmental Conservation, unpub. data).

During the 1999 WN virus outbreak, SI was the only NYC borough without a human case of WN virus infection. There were no WN virus-infected mosquitoes in the 13 pools collected from SI (a total of 51 adult mosquitoes) October 2-10 (2). The percentage of live wild birds with WN virus antibody in a September 1999 avian serosurvey was 2\% (1/43) on SI, compared with 5\% (1/20) in Brooklyn and 51\% (128/253) in Queens (N. Komar, pers. commun.). Among the eight WN virus-infected dead birds found on SI during 1999, seven were found during October.

We summarize key entomologic, avian, human, and equine surveillance findings from SI from the 2000 outbreak of WN virus, the first year of prospective surveillance for WN virus infection among mosquitoes, birds, horses, and humans in NYC. The results from SI are compared with the other NYC boroughs. 


\section{West Nile Virus}

\section{Methods}

\section{Adult Mosquito Collection}

Adult mosquitoes were collected one night per week from May 2 through November 17 by using CDC miniature light traps baited with dry ice and CDC gravid traps at 21 locations on SI (Figure 1) and 80 locations in the other boroughs. During August 14 to September 2, adult mosquitoes were collected 5-7 nights per week on SI as part of an evaluation of the efficacy of adult mosquito control. All traps were set in the late afternoon and evening and retrieved the following morning. Specimens were immediately frozen with dry ice.

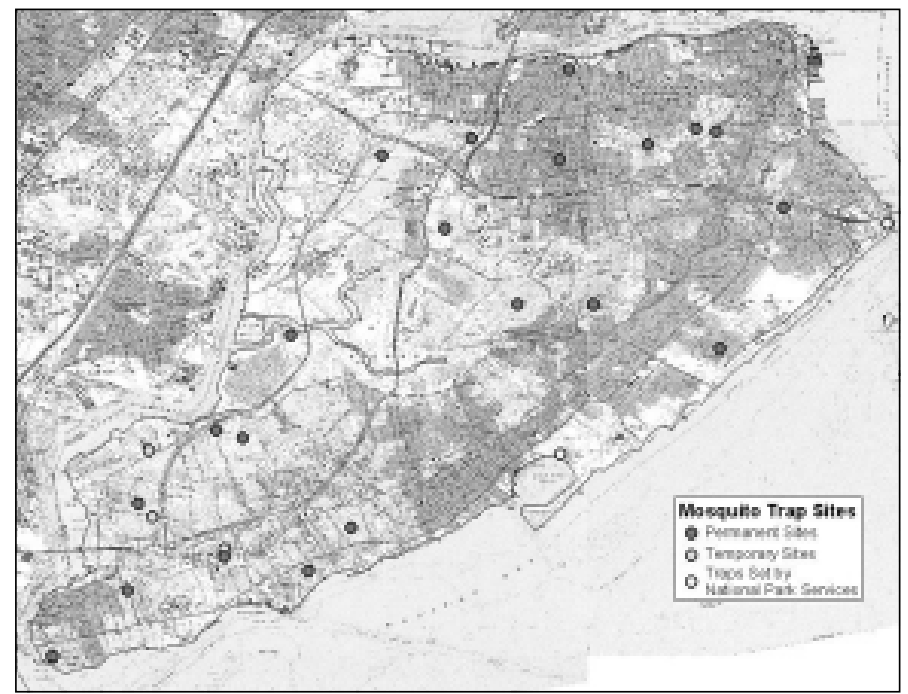

Figure 1. Mosquito trap locations, Staten Island, 2000. NPS = National Park sites.

Adult mosquitoes were identified and sorted to species whenever possible. If the condition of a specimen did not permit species identification, specimens were grouped as $C x$. pipiens / restuans or by genus alone. Up to 50 adult mosquito specimens were pooled (pools of $C x$. salinarius had up to 100 specimens) by trap site and date. Mosquito pools collected from May 2 to June 2 were submitted to the Centers for Disease Control and Prevention laboratory in Fort Collins, Colorado, and pools from June 3 to November 17 were submitted to the Arbovirus Laboratory of the New York State Department of Health (NYSDOH) for testing.

Minimum infection rate (MIR) was used as the index of virus activity in mosquito populations. MIR is calculated as the number of WN virus-positive pools per number of adult mosquitoes tested and is expressed as the number positive per 1,000 tested. Weekly MIRs were calculated for each species collected on SI and the other boroughs. Mosquito data include only those specimens that were sorted and tested as of December 2000.

\section{Dead Bird Reporting and Collection}

Dead bird reports were taken from the public by two systems. An interactive voice-response telephone system allowed callers to leave detailed information about the bird(s) being reported in a recorded message. Reports could also be entered onto a form on the NYCDOH web site. In both systems, the reporter was asked to provide the date the bird was initially found; its exact location, including street address, borough (county), and zip code; species; and cause of death (if known). The density of reported dead birds per square mile of surface area was determined by week for SI and the other boroughs.

Dead bird reports were reviewed before data entry; those meeting predetermined criteria were collected for WN virus testing. Collection was limited to birds recently dead (found in the previous 24 to 48 hours) and in relatively good condition (e.g., little or no decay). The primary criterion for collection was the species of bird. Initially only crows (American or Fish), sparrows, Blue Jays, or any cluster of five or more birds were collected for testing. Collection was expanded to include other species, resources permitting, if they were in good condition. Collection of other species focused on raptors (especially Merlins and American Kestrels) or species not typically reported (e.g., Black Skimmer, Belted Kingfisher). Collected birds were sealed in plastic bags and stored with freezer packs in the field. All specimens were submitted to the Wildlife Pathology Unit of the New York State Department of Environmental Conservation for necropsy; tissue specimens were submitted to the Arbovirus Laboratory of the NYSDOH for WN virus testing.

\section{Laboratory Testing of Mosquitoes and Birds}

Adult mosquito pools and avian tissues were tested for WN virus with one set of primers/probes by real-time reverse transcription-polymerase chain reaction (RT-PCR) (TaqMan, ABI Prism 7700 Sequence Detector, Applied Biosystems, Foster City, CA). Confirmatory tests were performed by using a second TaqMan primer/probe set, standard RT-PCR, virus isolation in cell culture, and immunofluorescence assays (avian tissues). A sample was confirmed positive when at least two different tests were positive. Details on virus testing are described elsewhere $(4,5)$.

\section{Human and Equine Case Surveillance}

NYCDOH conducted citywide enhanced passive and active hospital-based physician and laboratory surveillance for human WN virus infections, including all three acute-care hospitals on SI. Additional details on human surveillance are described elsewhere in this journal by Weiss et al. (6). Surveillance for equine illnesses was by enhanced passive surveillance. Additional details regarding equine surveillance are described elsewhere in this journal by Trock et al. (7).

\section{Results}

\section{Adult Mosquito Collection and Testing}

A total of 24,068 adult mosquitoes from 23 species were tested in 967 pools from SI; 131 pools from 6 species had laboratory evidence of WN virus. NYSDOH reported WN virus isolation from Aedes vexans, Cx. pipiens, Cx. salinarius, Ochlerotatus triseriatus, and Psorophora ferox, and WN viral RNA detection in Anopheles punctipennis (8). During the same period, a total of 51,044 adult mosquitoes from 26 species were tested in 1,958 pools collected from the other boroughs; 39 of these pools had laboratory evidence of WN virus (Table). These are the first reports of Ae. albopictus and $C x$. erraticus from New York State.

Laboratory evidence of WN virus was first detected from mosquitoes in a $C x$. pipiens pool collected July 7 and in a 


\section{West Nile Virus}

Table. Adult mosquitoes collected and tested from New York City (NYC), as of December 2000a

\begin{tabular}{|c|c|c|c|c|c|c|c|}
\hline \multirow[b]{2}{*}{ Genus } & \multirow[b]{2}{*}{ Sp. } & \multicolumn{3}{|c|}{ No. of mosquitoes tested } & \multicolumn{3}{|c|}{ No. of positive pools } \\
\hline & & Staten Island & Other boroughs & All NYC & Staten Island & Other boroughs & All NYC \\
\hline Aedes \& Ochlerotatus & species & 351 & 1,284 & 1,635 & 1 & & 1 \\
\hline \multirow{2}{*}{ Aedes } & albopictus & & 90 & 90 & & & \\
\hline & vexans & 2,497 & 3,215 & 5,712 & 2 & 2 & 4 \\
\hline \multirow[t]{4}{*}{ Anopheles } & crucians & 11 & 2 & 13 & & & \\
\hline & punctipennis & 47 & 3 & 50 & 1 & & 1 \\
\hline & quadrimaculatus & 44 & & 44 & & & \\
\hline & species & 16 & 37 & 53 & & & \\
\hline \multirow[t]{2}{*}{ Coquillettidia } & perturbans & 35 & 3,010 & 3,045 & & & \\
\hline & species & 6 & 6 & & & & \\
\hline \multirow{7}{*}{ Culex } & erraticus & 4 & & 4 & & & \\
\hline & pipiens & 4,820 & 15,231 & 20,051 & 55 & 19 & 74 \\
\hline & pipiens/restuans & 2,554 & 11,190 & 13,744 & 24 & 9 & 33 \\
\hline & restuans & 439 & 2,480 & 2,919 & & & \\
\hline & salinarius & 10,057 & 7,687 & 17,744 & 28 & 4 & 32 \\
\hline & territans & 28 & 45 & 73 & & & \\
\hline & species & 2,242 & 3,502 & 5,744 & 16 & 4 & 20 \\
\hline \multirow[t]{9}{*}{ Ochlerotatus } & canadensis & 21 & 277 & 298 & & & \\
\hline & cantator & 14 & 97 & 111 & & 1 & 1 \\
\hline & excrucians & 2 & & 2 & & & \\
\hline & intrudens & & 21 & 21 & & & \\
\hline & japonicus & & 2 & 2 & & & \\
\hline & sollicitans & 33 & 1,699 & 1,732 & & & \\
\hline & taeniorhynchus & 1 & 118 & 119 & & & \\
\hline & triseriatus & 592 & 180 & 772 & 3 & & 3 \\
\hline & trivittatus & 193 & 784 & 977 & & & \\
\hline \multirow[t]{2}{*}{ Psorophora } & $\begin{array}{l}\text { ferox } \\
\text { columbiae }\end{array}$ & 39 & 19 & 58 & 1 & & 1 \\
\hline & species & & 1 & 1 & & & \\
\hline Uranotaenia & sapphirina & 28 & & 28 & & & \\
\hline Unidentified, damaged & & & 64 & 64 & & & \\
\hline Total & & 24,074 & 51,044 & 75,106 & 131 & 39 & 170 \\
\hline
\end{tabular}

aPools were collected by the New York City Department of Health, the Centers for Disease Control and Prevention, the National Park Service, and the U.S. Army.

Cx. salinarius pool collected July 17 , both from SI. The first human patient on SI became ill on July 20. Additional human cases on SI had onset of disease between July 28 and September 2. Human cases occurred when the MIR among $C x$. pipiens and $C x$. pipiens/restuans ranged from approximately 5 to 16/1,000 (July 7 to September 22) and the MIR among Cx. salinarius was at least 4/1,000 (6 of 7 weeks from July 15 to September 1). The MIR among $C x$. salinarius peaked at 9/1,000 in the week ending August 11 (Figure 2).

\section{Dead Bird Reports and Testing}

Overall, 14,849 dead birds were reported in NYC during 2000 , including 4,910 (33\%) from SI. Of the SI birds, 235 $(4.8 \%)$ were collected and submitted for testing; $60(26 \%)$ had laboratory evidence of WN virus. These included 45 American Crows, 5 Blue Jays, 2 Snowy Owls, and 1 each of the following species: American Kestrel, Canada Goose, Common Grackle, Fish Crow, Greater Black-backed Gull, Mourning Dove, Northern Mockingbird, and sparrow.

Density of total dead birds per square mile on SI began to increase the week ending July 7 and peaked at $>14$ dead birds/ square mile per week during the week ending July 21 . The density of dead birds remained $>5$ /square mile until the week ending September 1. This period of increased weekly den-sity of dead birds coincided with the period of elevated MIRs among $C x$. pipiens, $C x$. pipiens / restuans, and $C x$. salinarius (Figure 2 ).

\section{Human and Equine Cases}

Ten human cases of neurologic WN virus infection were reported from SI, and four cases were reported from three other boroughs. Onset of illness for the SI cases ranged from July 20 to September 2 and from August 15 to September 13

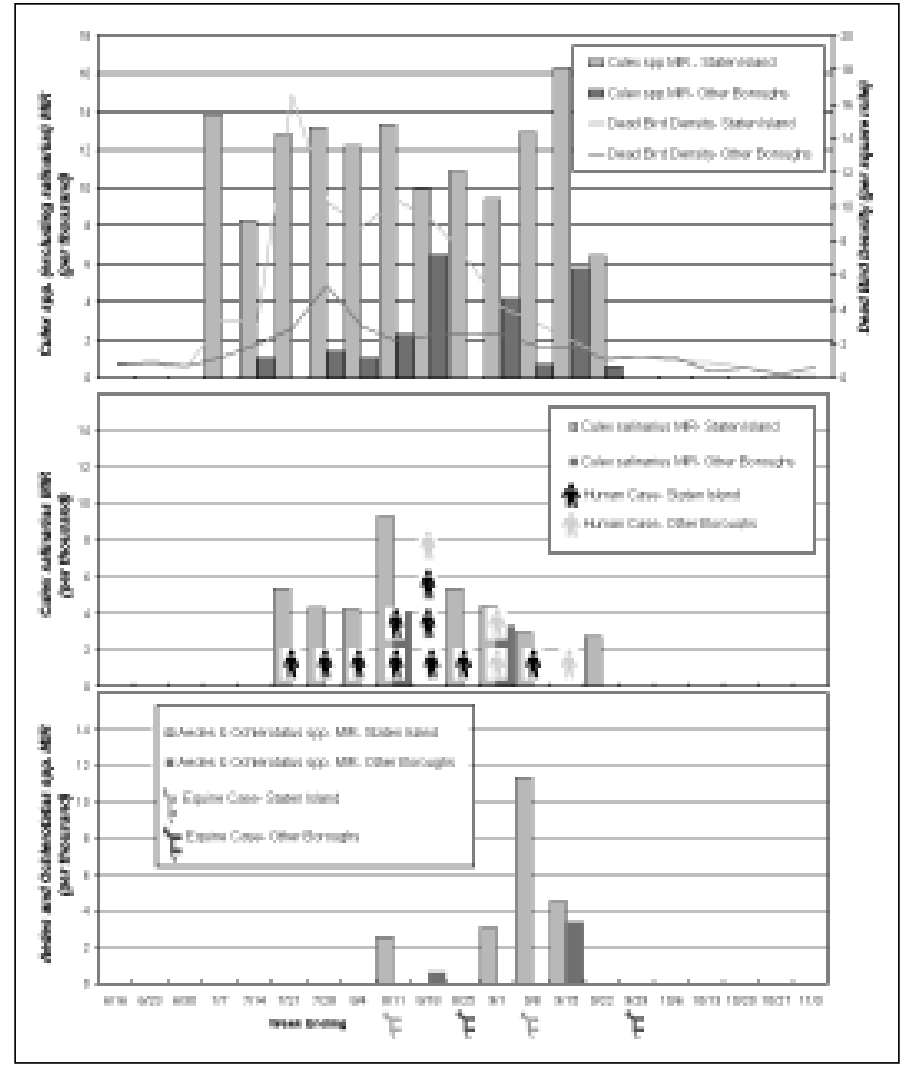

Figure 2. Minimum infection rate (MIR) of Culex pipiens / restuans, Cx. salinarius, Aedes sp., and Ochlerotatus sp., dead bird densities, West Nile-infected human and equine cases by week, Staten Island and other boroughs, New York City, 2000 


\section{West Nile Virus}

for the other boroughs. Four confirmed equine cases were reported, two on SI (onset August 17 and September 8) and two from another borough (onset August 27 and October 1).

\section{Conclusion}

All 10 human infections with WN virus on SI in 2000 occurred when the weekly density of dead birds and mosquito MIRs was elevated. Dead bird density increased to three dead birds/square mile and the MIR for $C x$. pipiens and Cx. pipiens/restuans increased to 8-14/1,000 mosquitoes before the first human case was reported. Monitoring dead bird density and mosquito MIRs may detect increased WN viral activity and predict when the risk of human infection with WN virus is increased.

The first human patient on SI had onset of symptoms on July 20; if one assumes a 3- to 15-day incubation period for WN virus (9), exposure to a WN virus-infected mosquito would have occurred between July 5 and July 17 . WN virus was first detected in a pool of $C x$. pipiens collected on July 7 and in a $C x$. salinarius pool collected on July 17 from different sites approximately 2 miles from the residence of the first human case. Additional human cases on SI had onset of disease between July 28 and September 2, with exposure to a WN virus-infected mosquito estimated to be between July 13 and August 29. MIRs remained elevated during this period. Based on the observations on SI, we propose a model of transmission that may be applicable to similar habitats elsewhere in the northeastern United States. Cx. pipiens and $C x$. restuans appear to serve as the primary enzootic and epizootic vectors among birds. Blood-meal analyses of mosquitoes collected in NYC during 2000 show that $C x$. pipiens feeds predominantly on birds (Charles Apperson, pers. commun.), consistent with an earlier observation by Spielman (10). This interaction appears to amplify the amount of virus circulating in spring and early summer. Cx. salinarius appears to serve as the bridge vector for human transmission. This mosquito has also been hypothesized as a bridge vector for human transmission of eastern equine encephalomyelitis virus (11). Aedes / Ochlerotatus spp. appear to be infected later in the season and serve as bridge vectors for horses.

There are several important limitations to the observations reported in this paper. The data presented reflect a single year of data, and additional surveillance data over time will be needed to determine if there is a consistent correlation between increased dead bird density, elevated mosquito MIRs, and human case onset.

The advance warning provided by dead bird and mosquito data appears to be limited to no more than 10 days. While dead bird reports can be monitored daily and a weekly dead bird density can be quickly determined, MIR data require the labor-intensive and time-consuming steps of pooling by species and laboratory testing. The usefulness of MIR data depends on timely completion of these tasks.

Polymerase chain reaction (PCR) was the primary method of laboratory testing of birds and mosquitoes from SI, and viral culture was not performed to confirm the presence of live WN virus in all specimens. The interpretation of PCR results without viral confirmation requires caution. However, vector competence for WN virus transmission has been demonstrated for Ae. vexans, Cx. pipiens (12), Cx. salinarius (Michael Turell, unpub. data), and Oc. triseriatus (Michael Turell, pers. commun.). These four species made up 98\% (112/
114) of the positive mosquito pools sorted to species from SI reported in this paper. Vector competence has not been determined for Ps. ferox or An. punctipennis.

Dead bird data are limited in that avian mortality is not an established surveillance method for which baseline rates are known. We are unable to compare the number of dead birds reported on SI in 2000 with a prior year's data. Furthermore, public interest in reporting dead birds could wane over time, limiting the usefulness of this surveillance technique.

The dead bird densities shown in this paper were calculated at the borough (county) level, and analysis at smaller geographic units may detect more focal areas of transmission that are at greater risk for human infection than surrounding locations. Additional surveillance methods, e.g., live bird surveillance or use of sentinel animals, may provide a more timely warning of increasing risk of human WN viral infection.

\section{Acknowledgments}

Among the hundreds of coworkers at our institutions who contributed to the West Nile virus response, the authors thank Ward Stone for avian tissue processing, Jason Thomas and Colonel Charles Cannon for providing adult mosquito collection and testing data, Lisa Mill for assistance with adult mosquito sorting, Marci Layton for providing comments on the draft, Susan Resnick for preparation of the map, Varner Demary for supervising adult mosquito collection, the staff of the New York State Department of Health Arboviral Laboratory for testing avian tissues and mosquito pools, and Kristy Gottfried, Kristy Burkhalter, and Amy Kerst for assistance in testing mosquito pools.

Dr. Kulasekera is a research scientist in charge of the mosquito surveillance program in New York City. Her research interests include ecologic and evolutionary interactions among mosquitoes and the pathogens they transmit.

\section{References}

1. Centers for Disease Control and Prevention. Outbreak of West Nile-like viral encephalitis-New York, 1999. MMWR Morb Mortal Wkly Rep 1999;48:846.

2. Nasci RN, White DJ, Stirling H, Oliver JA, Daniels TJ, Falco RC, et al. West Nile virus isolates from mosquitoes in New York and New Jersey, 1999. Emerg Infect Dis 2001;7:626-30.

3. City of New York. The 1998-99 green book, official directory of the City of New York. 73rd ed. New York: City of New York; 1998:607-8.

4. Kramer LD, Bernard KA. West Nile virus tissue tropisms in birds and mammals. Ann NY Acad Sci 2001; in press.

5. Shi P-Y, Kauffman EB, Ren P, Felton A, Tai JH, Dupuis II AP, et al. High throughput detection of West Nile virus RNA. J Clin Microbiol 2001;39:1264-71.

6. Weiss D, Carr D, Kellachan J, Tan C, Phillips M, Bresnitz E, et al. Clinical findings of West Nile virus infection in hospitalized patients, New York and New Jersey, 2000. Emerg Infect Dis 2001;7:654-8.

7. Trock SC, Meade BJ, Glaser AL, Ostlund EN, Lanciotti RS, Cropp BC, et al. West Nile virus outbreak among horses in New York State, 1999 and 2000. Emerg Infect Dis 2001;7:745-7.

8. Bernard KA, Maffei JG, Jones SA, Kauffman EB, Ebel GD, Dupuis AP, et al. West Nile virus infection in birds and mosquitoes in New York State, 2000. Emerg Infect Dis 2001;7:679-85.

9. Olejnik E. Infectious adenitis transmitted by $C x$. molestus. Bulletin of the Research Council of Israel 1952; 2:210-11.

10. Spielman A. Population structure in the $C x$. pipiens complex of mosquitoes. Bull World Health Organ 1967;37:271-6.

11. Vaidyanathan R, Edman JD, Cooper LA, Scott TW. Vector competence of mosquitoes (Diptera: Culicidae) from Massachusetts for a sympatric isolate of eastern equine encephalomyelitis virus. J Med Entomol 1997;34:346-52.

12. Turell MJ, O'Guinn ML, Dohm DJ, Jones JW. Vector competence of North American mosquitoes (Diptera: Culicidae) for West Nile virus. J Med Entomol 2001;38:130-4. 